\title{
CARTOGRAFIA DO TRABALHO NA CIDADE-FLORESTA
}

\author{
Agenor Sarraf Pacheco \\ Universidade Federal Pará - Brasil
}

\section{RESUMO}

$\mathrm{O}$ artigo procura cartografar movimentos e sentidos empreendidos por habitantes do espaço rural e florestal melgacense, que se fizeram trabalhadores de carro-de-mão na cidade de Melgaço, situada no Arquipélago de Marajó, no Pará. Para alcançar esse objetivo, interagimos com memórias orais captadas em entre-vistas com esses trabalhadores migrantes, à luz da história oral, social e da cultura. Com isso, colocamos em evidência experiências de trabalho, negociações e lutas políticas que, na última década do século $\mathrm{XX}$, ressignificaram modos de vida nessa cidade-floresta.

PALAVRAS-CHAVE: Cartografia. Memória. Experiência. Trabalho. Cidade-Floresta.

\section{Mapeando a cidade-floresta}

São 14:00h, Melgaço está calma, o tempo da natureza rege a dinâmica urbana da cidade. $\mathrm{O}$ sol escaldante convida os moradores a permanecerem em casa, alguns caminham para assumir seus postos de trabalho no setor público, crianças e adolescente banham-se no rio para ir à escola e as calçadas vão sendo acordadas pelo barulho de carros de mão que começam a descer as principais ruas em direção ao trapiche municipal. São os carreteiros que, cortando sol e chuva, preparam-se para esperar os barcos da linha Melgaço-Breves, Breves-Melgaço. Barco, rio, maré sintonizam-se com o tempo de trabalho desses carregadores de mercadorias que entram e saem da cidade surgida numa enseada de águas, terras e matas.

A narrativa expressa parte do dia-a-dia vivido pela cidade de Melgaço, situada no ocidente marajoara, e pelas lutas enfrentadas por moradores de ambientes rurais-florestais, que foram se fazendo trabalhadores urbanos no território desta "cidade-floresta", 1 no espocar

1 "A expressão Cidade-Floresta remete a pensar noções de uma urbanidade singular que se elabora pelos saberes, linguagens e experiências sociais de populações formadas dentro de uma outra lógica de cidade, onde antigos caminhos de roças cedem lugar à construção de ruas de chão batido, depois asfaltadas, assim como a permanência de práticas de viveres ribeirinhos nesses novos espaços de moradia. Pensar Melgaço como 
da década de $1990 .{ }^{2}$ Cartografar ${ }^{3}$ o movimento empreendido por esses trabalhadores para visibilizar experiências de trabalho, formas de viver em Melgaço e aprender lutas, negociações, ressignificações da/na "cidade-floresta", constituem-se objetivos deste artigo.

Antes de acompanharmos os modos como esses trabalhadores envolveram-se na prática de carreteiros, faz-se necessário dizer que esse tipo de trabalho não é exclusivo de Melgaço. Apesar de esta "cidade-floresta" ser o nosso local de pesquisa, o trabalho com carros de mão é muito presente em algumas cidades que formam o mapa, tanto do Marajó das Florestas e dos Campos, quanto de outras cidades paraenses. Se o leitor mergulhar nesse universo para tentar compreender a vida e o trabalho dos carreteiros, uma pergunta possivelmente fará: O que teria levado populações de tradições orais e rurais a inventarem esse tipo de trabalho nessas cidades marajoaras? Em que elas se ins-

uma Cidade-Floresta levou-me a relacionar sua trajetória de constituição com outros municípios marajoaras que se forma em seus aspectos físicos, humanos e culturais em terras firmes e de várzeas, por ribeirinhos, caboclos, descendentes do enfrentamento cultural de índios, africanos escravizados e colonizadores brancos, bem como com a chegada de nordestinos, num tempo em que o ouro negro transformou espaços amazônicos e produziu contradições no viver regional" (PACHECO, 2006, p. 24).

2 Boa parte dos anos de 1990 foi, para a história política do município, um tempo de perdas e retrocessos. A chegada de políticos irresponsáveis com o uso e aplicação de recursos e bens públicos causou transtornos, dores e revoltas no seio da população. Em virtude da difícil situação que o município viveu, a partir da década de 90, intensificando-se no período de 1993/96, surgiu na cidade um novo tipo de trabalho - os carreteiros. As razões que levaram populações a migrarem e a buscarem no carro-de-mão uma estratégia para o viver urbano, serão apresentadas ao longo deste artigo.

3 Trabalho com o sentido de cartografia como a concebe Martín-Barbero (2004, p. 13). Para ele, trata-se de "mapas cognitivos que traduzem outras figuras como a do arquipélago, desprovidas de fronteiras que os una. Com isso, o continente se desagrega em ilhas múltiplas e diversas, que se interconectam". Aplicando o conceito a proposta do artigo, apreendo a cartografia como a confecção de um mapa fragmentado, plural, aberto e em conexão, desenhado por fios de memórias para se alcançar as experiências de trabalho e vida dos carreteiros na cidade. Assim, explorar o cotidiano de trabalho é mergulhar no fazer-se da cidade de Melgaço em suas singularidades rurbanas. 
piraram para pensar nessa possibilidade de garantir a continuidade da vida pessoal e familiar?

Para responder as duas questões apresentadas, precisamos reportar-nos para as mudanças nos modos de vida na mata. Em seguida, torna-se necessário refletir a respeito de saberes e experiências que transmigram junto com mulheres e homens do Marajó das Florestas, tais como: plantas, animais de criação e seus bens materiais, quando traçam em suas experiências de vida o desejo de morar em uma cidade, mesmo que esta não apresente possibilidades de emprego fácil, como era o caso de Melgaço, no contexto de 1990 a 2002, para os carreteiros com os quais interagíamos via metodologia da História Oral.

A região de Marajó, por ser formada por ilhas, composta por áreas de tesos, também chamados de terra firme, raramente atingida pelas cheias, além de terras de várzeas e igapós, constituídos pelas dinâmicas de águas e terras, comporta diferentes usos destes recursos por trabalhadores rurais. É comum encontrarmos, nas terras firmes, carroças sendo conduzidas por bois, pessoas puxando pequenos carros de mão ${ }^{4}$ feitos de madeira ou de ferro, ajudando o homem do campo a transportar sua produção, tanto para a sede do município, quanto materiais que utilizam em trabalhos de roça ou fazendas de gado.

As terras que hoje dão origem a casas, prédios e ruas na cidade de Melgaço foram, no passado, roças, onde populações rurais plantavam mandioca, macaxeira, milho, maxixe, abóbora, melancia; e fazendas de criação de gado. Hoje, as fazendas desapareceram, mas os caminhos da roça continuam, apesar de seus deslocamentos, abrindo

4 É importante enfatizar que esses carros que os trabalhadores levavam para suas roças, muito eram feitos todo em madeira, inclusive seu processo de rolamento, tendo apenas a roda encapada com restos de pneu de bicicleta, carro ou trator. Hoje, parte dianteira ou traseira de carros usados é adquirida pelos carreteiros para confeccionar seu carro-demão, o que permite ser maior e mais resistente ao volume de pesos e mercadorias. 
espaços para o nascimento da "cidade-floresta". Esses caminhos tornaram-se um prolongamento da cidade, ligando-se a esta de forma tão intensa que se formos trafegá-los não saberemos definir precisamente onde termina a cidade e começa a estrada que leva os trabalhadores para suas roças e casas de farinha na floresta. Há alguns anos atrás, ouvíamos na cidade, frequentemente trabalhadores rurais, dirigiremse em grupo para suas roças, marcando como ponto de encontro à "boca da estrada". Atualmente, esse lugar se confunde com as novas ruas que ali foram abertas. Na verdade a boca da estrada foi consumida pela expansão da cidade, o que se observa são os imbricamentos cidade-floresta.

Outro aspecto interessante dessa dinâmica social refere-se à constituição de formas de viver e trabalhar nos espaços rurais e urbanos do município. Há pessoas que apenas moram no espaço urbano e trabalham no espaço rural; outras moram nos arredores da própria roça e usam dos espaços e bens da cidade apenas nos finais de semana, quando "descem" com sua produção para vender ou trocar por artigos ou gêneros que necessitam. Para "descer" com a produção, esses trabalhadores comumente usam pequenos carros-de-mão ou carregam nas costas ou ainda, quando conseguem, trazem no caminhão doado pelo governo estadual, que na década de 1990 dificilmente estava disponível, porque a prefeitura o usava para outros fins. ${ }^{5}$

À medida que a cidade foi crescendo e novas pessoas passaram a habitá-la, os pequenos carros que os trabalhadores usavam para transportar sua produção para o espaço urbano foi se tornando, também, meio de transporte de mercadorias que começaram a circular dentro da própria cidade. Um instrumento que fazia parte da cultura material do espaço rural migrou para a cidade-floresta, recebeu novos usos e

5 Na década de 1990, experienciando o trabalho na roça em Melgaço, ouvíamos muitas vezes os agricultores reclamarem a respeito do caminhão doado para o trabalho em roça que comumente a administração pública usava para realizar serviços no espaço urbano. 
apropriações, transformando-se em instrumento de luta pela reprodução da existência no espaço urbano. É preciso lembrar, contudo, que o carro-de-mão ainda que passasse a fazer parte da paisagem cultural da cidade, continua sendo utilizado pelos trabalhadores rurais, expressando trocas e ressignificações de saberes entre floresta e cidade.

\section{Des(a)fiando memórias do trabalho}

O interesse em construir entre-vistas com trabalhadores migrantes do espaço rural-florestal melgacense para a cidade de Melgaço, objetivando captar memórias e experiências de vida e trabalho foi despertado quando passamos a observar que o cotidiano da cidade de Melgaço, no contexto da década de 1990, vinha sofrendo alterações. Novos sujeitos sociais ligados ao mundo do trabalho estavam movimentando o fluxo pessoas e mercadorias que entravam e saiam da cidade. Deste modo, na perspectiva de cartografar essa dinâmica urbana, começamos a escrita deste texto com o depoimento de seu Daniel que socializou seu envolvimento com o carro-de-mão, há 20 anos, quando apenas duas pessoas trabalhavam nesta atividade em Melgaço, sendo que uma delas havia falecido e a outra migrou para Breves.

Em Breves, o trabalho com carros de mão constitui-se em prática anterior a de Melgaço, por ser um município pólo na parte interna do Marajó das Florestas. A formação de seu espaço urbano ocorreu anteriormente a de outros municípios do lado ocidental marajoara. Segundo os carreteiros entrevistados, o constante contato com Breves e Melgaço, tanto no que diz respeito às relações comerciais, quanto as de parentesco ali constituídas, ampliaram-se quando o desemprego se intensificou nesses lugares, impulsionado por frequentes migrações de pessoas que foram deixando as matas e passaram a habitar as nascentes cidades. Daí, percebemos que o trabalho com carros representou uma possibilidade de manter a chama da vida acesa para essas pes- 
soas, conforme depoimento de seu Lino, que explicita essa movência mata/cidade, ocupações em serviços públicos, atividades particulares.

Quando eu cheguei aqui em Melgaço em 1993 eu passei a trabalhar na prefeitura e aí houve aquele problema com a administração do Oni e quando encerrou os quatro anos, já com a intervenção do Capitão, a coisa também não havia melhorado. Nessas alturas eu fiquei desempregado, e desempregado pensei em voltar ao interior, mas com a dificuldade da vida no interior e não querendo atrapalhar o estudo dos filhos, eu fiquei indeciso o que deveria fazer, aí eu olhei para um carreteiro que se chama Daniel Pinheiro eu olhei e disse: - Poxa, ele está vivendo como carreteiro, eu também vou consegui um carro, e aí eu pensei nisso e justamente consegui um carro. ${ }^{6}$

Inspirado no trabalho com carros de mãos já desenvolvido em Melgaço por seu Daniel e seus filhos, seu Lino foi observando que essa atividade poderia garantir o sustento de sua família, desempregada em função da crise administrativa que o município enfrentou no contexto de 1993-1996. Vivendo essa pressão, entrou em contato com o universo de carregar mercadorias e cargas na cidade.

Migrando da mata e trazendo consigo experiências de trabalho e saberes pouco valorizados no universo onde se inseriu inicialmente o de funcionário na prefeitura -, mesmo sofrendo a demissão por ter assumido cargo público de confiança e temporário, não sentiu vontade de retornar para seu lugar de origem. O desejo de colocar os filhos para estudar e de vir residir na sede de sua terra natal motivou-lhe a enfrentar sacrifícios e necessidades postas pelo viver naquela cidadefloresta marajoara.

Seu Lino explicou que deixou o interior do município ao ser convidado, pelo candidato a prefeito Antônio Oni, a morar e trabalhar em Melgaço, com a garantia de emprego para ele e seus filhos de maior idade. Como o candidato ganhou as eleições, seu Lino "remou" para a

6 Entrevista com Lino Corrêa de Araújo, 55 anos. Melgaço, 29 de novembro de 2002. 
cidade. Visualizando sua trajetória de vida e acompanhando a chegada de outros habitantes do meio rural melgacense, percebemos que dentre os vários motivos detonadores desse fluxo mata-cidade, promessas políticas de empregos públicos foram e são decisivas nesse processo de deslocamentos. Candidatos a vereadores, especialmente a prefeito e vice-prefeito, modificam espaços da cidade, não apenas por suas ações administrativas, mas também pela instalação de seus familiares, parentes, amigos na sede do município que o elegeu.

Muitos desses moradores da floresta deixaram suas propriedades na esperança de conseguirem um emprego na prefeitura, o principal posto de serviço da cidade. ${ }^{7}$ Quando conseguem o tão sonhado emprego, a falta de formação nas letras os destina a serem vigias, capinadores de rua, ajudantes de pedreiros e tantos outros cargos pouco valorizados e vistos como descartáveis pelos administradores e pela própria comunidade local. Aprofunda essa questão o fato de as administrações serem gerenciadas por pessoas com pouca ou quase nenhum competência para legislar ou conduzir a vida pública. A vida profissional desses funcionários fica a mercê de critérios implementados pela forma tradicional de se fazer política administrativa no município. Assim, hoje funcionário, amanhã procurando outros afazeres.

7 Melgaço durante sua história nunca contou com a presença de grandes indústrias no espaço urbano. Segundo depoimento de moradores antigos, na década de 1970, apareceu na cidade um empresário que recorreu ao prefeito da época, Hermógenes F. dos Santos, dizendo que gostaria de comprar um lugar para montar uma fábrica de palmitos. O melhor lugar que a cidade possuía era onde funcionava a sede dançante, ao lado da antiga prefeitura queimada em 12 de agosto de 1996, na avenida Senador Lemos. O prefeito, depois de consultar e ser referendado pela população a respeito da liberação desse local para funcionar a fábrica, já que prometeu com o dinheiro da venda construir uma nova sede dançante, negociou o prédio com a empresa de conservas de palmito. Essa fábrica empregava mais ou menos 40 pessoas, porém, não teve vida longa, decretando falência no início dos anos de 1980. Depois surgiu na cidade uma outra fábrica de palmito, só que desta vez menor, empregando apenas 20 funcionários diretamente; com o endividamento de seu proprietário, também decretou falência e fechou suas portas no final dos anos de 1990. 
Sem estabilidade funcional, já que as administrações até o final do século XX não demonstravam nenhum interesse em realizar concursos públicos ou estabelecer leis justas para que os funcionários tivessem sem direitos trabalhistas garantidos, conviver com a instabilidade da vida pública e urbana era/é característica do modo de vida de muitos trabalhadores da prefeitura. A situação de descaso e descompromisso por parte da administração municipal é tanta que muitos funcionários, na mudança de prefeito, são demitidos sem nenhum direito trabalhista.

Fato curioso ocorrido quando estávamos fazendo a pesquisa, foi sermos surpreendido por um dos moradores que nos aguardava em sua casa ansioso e com uma certidão de tempo de serviço nas mãos. Ali, antes de iniciarmos a entrevista, em silêncio entregou-nos um documento, como quem dissesse - Lute pelos meus direitos! Fui desrespeitado! Desvalorizaram-me! Enquanto ouvíamos o depoimento sobre sua vida e olhávamos aquele papel amarelo em nossas mãos, fomos tomando conhecimento de que seu Manoel Soares de Oliveira, popularmente conhecido na cidade como seu Grosso, tinha sido desde 1962, o primeiro trapicheiro e acendedor do lampião que iluminava o trapiche municipal, na época em que a luz elétrica não chegava até o trapiche, dificultando o atracar de barcos à noite, na nascente "cidade-floresta". Com a mudança de governo, entre os anos de 1992/93, o antigo trapicheiro foi "jogado fora do cargo" sem nenhuma explicação do novo administrador. Trinta anos de trabalho desapareceram em meio a ações irresponsáveis e de interesse particular na vida pública.

O que aconteceu com seu Manoel, retrata como o quadro de funcionários da prefeitura modificava-se, constantemente, desvalorizando profissionalmente esses trabalhadores. Tal movimento de entrada e saída de funcionários era marcado pelas mudanças de prefeitos e vere- 
adores e oscilações no gerenciamento dos recursos públicos. A política assistencialista adotada pelas elites políticas, tanto de Melgaço quanto de outros municípios paraenses, sintetiza, em parte, a concepção de gestão pública adotada nesses lugares. Para essas administrações, o trabalhador público é visto como descartável.

A respeito dessas tramas constituídas do social entre moradores e políticos locais, alguns desses trabalhadores rurais, ao chegarem à cidade, percebem que o sonho de ser funcionário da prefeitura vai se desfazendo e para continuarem moradores daquele lugar torna-se fundamental "inventar" atividades mutantes e provisórias no relacionarse com a vida urbana de Melgaço.

Seguindo os envolvimentos desses habitantes da floresta com atividades em carros-de-mão, solicitamos a seu Daniel que explicasse como se fez carreteiro. Com olhar sereno, calmo, típico de seu jeito de ser, a princípio com certo medo de falar, por achar que não sabia utilizar as palavras corretamente, narrou:

Eu fui chamado a ser candidato a vereador com o Oni. Nesse tempo minha esposa adoeceu e ele não teve como me ajudar e eu fui informado por um amigo meu que o Taveira, que era o prefeito atual, nos ajudaria se eu trabalhasse com ele, aí eu trabalhei com o Taveira e no final o candidato do Taveira perdeu aí nós chegamos pra ele e dissemos: - Seu Taveira é o seguinte, nós perdemos a eleição, o senhor vai embora, porque o senhor foi contra o prefeito, agora eu preciso ficar aqui em Melgaço, mas no que eu vou trabalhar? Só se o senhor me der uma ajuda. Aí eu pensei no carro-de-mão, que naquela época ganhava muito dinheiro mesmo, era melhor pra mim. Aí ele me deu o carro-de-mão, aí foi o início do meu trabalho de carro, foi assim, dado pelo prefeito. Eu ganhei muito dinheiro mesmo com isso daí. ${ }^{8}$

Estabelecer vínculos com políticos locais para resolver problemas vividos diariamente, especialmente de saúde e trabalho, tem sido prática muito utilizada por moradores para exigir o cumprimento de

8 Entrevista com Daniel Pinheiro da Silva, 62 anos. Melgaço, 30 de novembro de 2002. 
seus direitos. Cobrar dos representantes políticos do município esses direitos expressos nas legislações municipais, estaduais e federais, através de pactos sociais, como narra seu Daniel, permite compreender o uso que políticos fazem dos poderes a eles atribuídos nas eleições, como se relacionam com a população e os jogos de trocas de favores que programam para permanecerem no cargo, reatualizando atitudes tão antigas na política brasileira e que, ainda hoje, permanecem em regiões do Brasil. Estas formas de luta por direitos sociais são recorrentes e assumem discursos de outras maneiras, como é o caso de Melgaço. Isso não significa dizer que esses moradores sejam ausentes ou passivos nas disputas políticas. A forma como seu Daniel dirigiu-se ao prefeito permite dimensionar sua atuação para se fazer cidadão da vida urbana.

A atitude tomada pelo narrador desmistifica a falsa ideia de que somente as pessoas organizadas possuem consciência política ${ }^{9}$ para perceberem o grau de sujeição imposta pelos que comandam os poderes públicos, políticos e econômicos de um lugar. Para além da concepção de percebê-lo como um homem calado, pacato, de postura conservadora, já que procura não se envolver em ambientes onde se encontram outros carreteiros com os mesmos problemas, emerge de sua fala a postura de um homem preocupado com as questões de seu tempo e interesse. Expressa em sua voz a vontade de falar dos outros carreteiros e moradores locais. Nesse contexto, fica perceptível que a relação entre moradores e políticos na cidade-floresta é alinhavada entre negociações, sociabilidades e litígios. Isso deixa ver que esses moradores reconhecem seus direitos, procuram, a sua maneira, exigir seu cumprimento.

9 Thompson (1987, p. 09) considera que falar em consciência é refletir sobre o papel que a experiência social desempenha nas vivências das pessoas. Nesse sentido, a consciência de classe nunca surge da mesma forma e nas mesmas circunstâncias vividas. Depende da cultura e dos modos como os sujeitos históricos compreendem suas ações e relações sociais. 
Na década de 1990, diariamente quando o prefeito encontrava-se na cidade e resolvia ir para a prefeitura, muitos moradores dirigiamse a ele para resolverem seus diversos problemas pessoais. Entre os pedidos, o que mais se destacava era o de alcançar um emprego na prefeitura. Não conseguindo, voltavam para suas casas com promessas de que um dia teriam, ou com a frase repetida nos quatro cantos da cidade - a prefeitura está inchada. ${ }^{10}$

Diante dessa realidade, o que fazem esses moradores? Muitos, ao chegarem à cidade e perceberem que o imaginário de terem uma vida melhor, muitas vezes divulgada por parentes e amigos, ${ }^{11}$ ou então visualizado por eles mesmos, não corresponde à situação vivenciada, retornam para a floresta ou para o lugar de onde vieram. Outros, mesmo passando a habitar a cidade, continuam desenvolvendo atividades braçais, como aconteceu com Moacir. "Quando eu cheguei aqui, comecei cortando palmito e, achei que tinha vindo pra cidade pra sair do mato né, realmente do gapó, aí passei a fazer roça, achei que não deu futuro pra mim, por causa que não dava pra suprir a minha necessidade, ai dei a usar o carro pra fazer carreto". ${ }^{12}$

10 Essa questão traz a tona discussões tão presentes no senado nacional a respeito da estrutura administrativa das cidades brasileiras. A esse respeito comenta Ermínia Maricato (2001, p. 74): “As estruturas administrativas urbanas são, na maioria dos casos, arcaicas. Elas estão viciadas em procedimentos baseados no privilégio e na troca de favores que são tradicionais na esfera pública dominada por interesses privados ligados aos governantes de plantão". Pensar a atual estrutura administrativa de um município é pensar na necessidade de se realizar a tão propalada reforma administrativa. No entanto, como afirma Maricato, é preciso, antes de mais nada, exigir a formação de um novo tipo de agente, seja funcionário público, vereadores, prefeitos, lideranças sociais, profissionais das ONGs ou do mercado privado. Maricato, (Idem, p.76).

11 No que concerne às imagens que são divulgadas por parentes e amigos sobre o viver na cidade é discutido por vários autores na historiografia brasileira, especialmente por aqueles que trabalham com a temática da migração ou imigração, dentre esses podemos citar Souza (1995).

12 Entrevista com Moacir Ferreira, 52 anos. Melgaço, 03 de dezembro de 2002. 
E ainda há aqueles que, compreendendo que não há mais possibilidades de continuarem habitando o espaço rural do município, pois as riquezas florestais que permitiam o sustento de sua família esgotaram-se, venturam-se $e^{13}$ a permanecer na cidade, forjando formas específicas e diversas de lutar pela existência, como tornar-se vendedor ambulante de sanduíches, doces, salgados, sucos, churrasco, frutas, tacacá, mingau, pão e outros; transformar a própria casa para servir de hospedaria, restaurante; montar pequenos bares para a venda de cerveja, refrigerante, cachaças e cigarros; trabalhar em parceria com outros moradores nas propriedades rurais que estão ligadas à cidade ou envolver-se com o trabalho em carros-de-mão, os conhecidos carreteiros, são algumas das muitas táticas de inclusão na vida urbana (CERTEAU, 1995).

A vida dos que habitam o espaço rural do município aos poucos também foi se modificando, em virtude de transformações ali desencadeadas. No entanto, a maioria ${ }^{14}$ ainda persiste e resiste, vivendo em contato com o meio natural que ainda lhes garante formas de produção da vida, convivendo com a idealizada "fartura" e, ao mesmo tempo, conscientes da "ventura" a que já começam a experimentar. Fartura pelo peixe, camarão, caça, açaí existente em algumas localidades. Fartura por poder usar a sabedoria adquirida por ancestrais em contato com os dinamismos da natureza. Fartura porque ainda têm um pedaço de roça de onde podem extrair seu sustento. Ventura porque sabem que um dia terão que "arribar" 15 de seu pedaço de chão

13 Estou tomando emprestado os conceitos de fartura e ventura do interessante trabalho de mestrado, já publicado de Santana (1998).

14 Segundo o censo 2010 do IBGE, a população total do município de Melgaço atingiu 24.808. Destes apenas 5.503 habitam o espaço urbano e 19.305 continuam residindo na meio rural do município.

15 Além da migração para a cidade, existe um processo peculiar no interior do município que temos denominado de migração interna, em que os moradores em função 
para outros lugares. Ventura porque são explorados pelos patrões ou comerciantes ambulantes, com quem são obrigados a vender ou trocar seus produtos. Ventura porque sabem que longe do acesso a códigos de vida urbana terão dificuldades para viver na cidade.

Essa ventura, vivida por ribeirinhos, tem se intensificado em virtude da falência ou fechamento, pelo IBAMA, de uma quantidade significativa de pequenas fábricas de palmito e serrarias de madeira que funcionavam, clandestinamente, no meio rural e florestal do município, sem nenhum projeto de reflorestamento. Soma-se a isso, a depredação e consequente esgotamento das convencionais riquezas naturais de suas localidades.

Esse processo de ventura acirrou-se mais ainda com a crise política que a administração municipal passou no período 1993/96, quando foram noticiados nos jornais impressos e televisivos, desvios e maus usos do dinheiro público, incompetência administrativa, falta de compromisso social do gestor municipal e outras irregularidades. Dessa forma, alguns desses moradores da floresta, não encontrando outras formas de lutar pelas condições de vida de sua família, resolvem migrar para a cidade e inventar novas formas de trabalho. O carro-de-mão emerge como instrumento a ser utilizado nesse processo de lutas em prol da existência humana.

"Aí dei a usar o carro pra fazer carreto, né, e tô achando que tá dando pra quebrar o galho, não como a gente espera, mas até que tá dando pra gente ir sobrevivendo aqui na cidade". ${ }^{16}$ Se na floresta, o casco, o remo e o rio eram os meios que lhes possibilitavam chegar a seu trabalho e sustentarem-se, na cidade o carro, os diversos materiais

do esgotamento das riquezas de uma determinada área onde moravam, "arribam" para outros recônditos da floresta em busca de lugares onde a natureza ainda guarda parte de sua riqueza.

16 Entrevista com Moacir Ferreira. Depoimento citado. 
que transportam e as ruas, substituíram seus antigos meios de aquisição de bens necessários à continuidade da vida. A exemplo de Moacir, muitas pessoas que passaram a residir em Melgaço a partir do início da década de 1990, começaram a envolver-se com atividades de transportar materiais diversos, porque se apresentava como uma das poucas oportunidades de trabalho na cidade.

Pela falta de recursos para adquirir seu próprio carro-de-mão, que custava em 2002 entre cem a duzentos reais, alguns fizeram opção de utilizar carros alugados de trabalhadores já consolidados no viver urbano. Sobre essa questão, ainda narra seu Moacir.

O pessoal implorava pra mim comprar um carro e a condição não tinha dado pra mim comprar, aí até que apareceu uma pessoa que fez um negócio comigo pra mim comprar um carro dele no valor de $\mathrm{R} \$ 90,00$. Ele me fazia de três prestação, meu filho ganhava uma gratificação das irmãs da igreja e nós negociamos com esse rapaz de eu dá trinta reais por mês pra ele e realmente era a taxa que meu filho ganhava, foi assim que eu comprei o primeiro carro. ${ }^{17}$

Incentivado por colegas de profissão, seu Moacir iniciou sua batalha para comprar seu próprio carro com a ajuda do dinheiro que o filho ganhava do trabalho desenvolvido na casa das irmãs da comunidade católica "Filhas da Divina Graça". ${ }^{18}$ Compreendendo que precisava ter seu próprio instrumento de trabalho, para desenvolver suas atividades de forma mais livre e não correr o risco de ficar devendo o aluguel para o proprietário, conversou com a esposa sobre a necessidade de melhor organizarem as economias da casa a fim de adquirirem o carro-de-mão.

Nesse universo de atividades entre carreteiros e usuários, emerge

\section{Idem.}

18 Trata-se de uma Casa de Missão, fundada em Melgaço em 1995, cuja sede principal fica na cidade de Soure. A comunidade missionária nasceu por iniciativa do bispo D. José Luís Azcona Hermoso. Para saber mais ver (PACHECO, 2009). 
a figura do proprietário de carros como uma espécie de intermediário nas relações de trabalho na cidade. Essas pessoas, contudo, até 2002 ainda eram raras, sendo que na pesquisa realizada descobrimos apenas duas. Um que é carreteiro e também aluga dois carros, outro que não exerce a profissão mais é dono de um carro-de-mão. Seu aluguel é cobrado diariamente, oscilando entre dois a três reais.

A ação desses trabalhadores não ocorre de forma igual. Alguns, mesmo possuindo o próprio carro, não estão a todo o momento acompanhando o cotidiano de trabalho dos outros carreteiros. Encontramos alguns de maneira mais presente e constante, correndo pelas ruas da cidade, outros raramente, talvez pelo fato da recente adaptação de seus músculos, que por se tratar de um trabalho pesado, cansativo e desgastante requer habilidades corporais diferentes das produzidas no cotidiano da floresta. Na fala de seu Lino, é possível visualizarmos essa questão e percebermos como os próprios carreteiros se veem nas atividades que desenvolvem.

"Olha, há uma diferença, há aqueles que têm vontade de trabalhar, que são esforçados no trabalho e têm aqueles que, dão uma moleza, só querem se for uma sacolinha, uma coisa pequena, quando alguém procura eles, assim numa carga mais pesada ele já não quer". ${ }^{19}$ $\mathrm{O}$ envolvimento com o carregar mercadorias e cargas diversas diferencia-se entre os mais de 20 carreteiros existentes em Melgaço em 2002. O trabalho com carros de mão, por constituir-se em atividade braçal, expondo o trabalhador ao sol e às chuvas, arriscando a própria vida, sinaliza para questões importantes a respeito das dificuldades que alguns têm para se adaptarem às árduas atividades exigidas por essa forma de trabalho.

Se alguns ainda encontram dificuldades para o manuseio com o carro, outros, já adestrados, alcançaram habilidades para sair rodando

19 Entrevista com Lino Corrêa de Araújo. Depoimento citado. 
com mercadorias e cargas pelas ruas da cidade; seus corpos vão ganhando formatos e contornos que se ajustam no manuseio desse instrumento de trabalho, que se configura como prolongamento de seu corpo. $^{20}$

Ao fazerem às vezes de animais, em comparação às atividades desenvolvidas por pequenas carroças, os corpos desses trabalhadores assumem formas impostas pelo trabalho como carreteiros. Suas mãos ficam grossas, seus corpos queimam, devido ao forte calor do sol e seus pés ficam mais grossos quando trabalham descalços. Nessa perspectiva, os corpos desses carreteiros refazem-se, assumindo feituras dos modos como lidam com suas atividades, forçando-os a passarem por um processo de domesticação corporal. ${ }^{21} \mathrm{O}$ viver urbano parece pressionar novas posturas a serem adotadas não apenas na utilização das linguagens, nos usos adequados de vocábulos e expressões de cordialidade nas relações que estabelecem com os usuários, mas também na remodelação de seus corpos que, apesar de se apresentarem no cenário urbano com traços de sensibilidades e sabedorias do viver e trabalhar na mata ressentem-se de habilidades que o trabalhar na cidade impõem aos que não têm experiências em desgastantes funções da vida urbana.

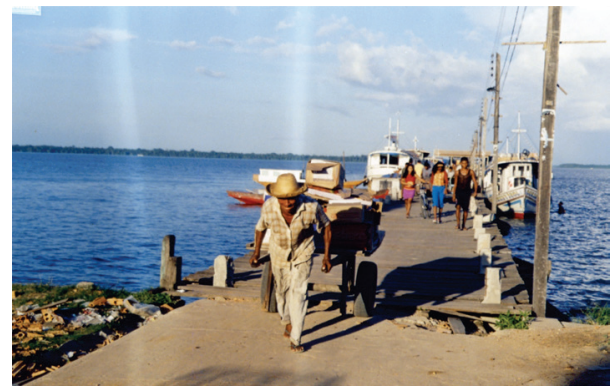

Carreteiros em atividade. Melgaço, 2001. Foto da pesquisa.

20 A respeito de artefatos que prolongam corpos para além de seus limites, ver (GIL, 1997, p. 254).

21 Sobre a domesticação de corpos na cidade, ver interessante artigo de (SANTANA, 2002). 
Retomando a questão sobre a diferença com que esses homens apresentam-se envolvidos com o carro-de-mão em Melgaço, seu Lino, juntamente com seus filhos, são surpreendidos pela necessidade de puxarem cargas, transportando os mais diversos materiais pelas ruas da cidade. Para termos uma ideia do seu entrosamento com esta atividade, lançamos mão de sua entrevista: "Comecei com um carro pequeno, atualmente nós temos 07 carros, dos quais trabalhamos em 05, incluindo o do Haroldo e outros 02 são alugados". ${ }^{22}$

$\mathrm{Na}$ conversa realizada com seu Lino, visualizamos um pouco de sua organização e intenso envolvimento com esse ramo de trabalho. Dos sete carros que possuía, cinco estavam sendo usados pela família que, além dele, incluía filhos e genros. Algo que muito impressionou foi quando mostrou um caderno, onde anota, diariamente, quanto ganhava nos carretos que realizava. Ao final do mês, somava o que adquiria com o carro em que trabalhava e com os dois carros alugados.

Tentando traduzir, em versão mais compreensiva ao universo de leitores, sem pretender dar conta da riqueza desse documento, das anotações foi possível construir a seguinte tabela:

\begin{tabular}{c|c|c|c} 
MÊS & CARRO PRÓPRIO & CARRO ALUGADO & TOTAL \\
Janeiro & $\mathrm{R} \$ 166,00$ & $\mathrm{R} \$ 15,00$ & $\mathrm{R} \$ 181,00$ \\
Fevereiro & $\mathrm{R} \$ 177,50$ & $\mathrm{R} \$ 61,00$ & $\mathrm{R} \$ 238,50$ \\
Março & $\mathrm{R} \$ 207,00$ & $\mathrm{R} \$ 70,00$ & $\mathrm{R} \$ 277,00$ \\
Abril & $\mathrm{R} \$ 206,50$ & $\mathrm{R} \$ 60,00$ & $\mathrm{R} \$ 271,50$ \\
Maio & $\mathrm{R} \$ 195,00$ & $\mathrm{R} \$ 30,00$ & $\mathrm{R} \$ 225,00$ \\
Junho & $\mathrm{R} \$ 292,00$ & $\mathrm{R} \$ 38,00$ & $\mathrm{R} \$ 330,00$ \\
Julho & $\mathrm{R} \$ 392,00$ & $\mathrm{R} \$ 110,00$ & $\mathrm{R} \$ 392,00$ \\
Agosto & $\mathrm{R} \$ 530,00$ & $\mathrm{R} \$ 101,00$ & $\mathrm{R} \$ 5330,00$ \\
Setembro & $\mathrm{R} \$ 429,50$ & $\mathrm{R} \$ 152,00$ & $\mathrm{R} \$ 553,50$
\end{tabular}

Fonte: Caderno de anotações do seu Lino Corrêa, ano, 2002.

Ao traduzirmos a referida tabela, nossa pretensão não é fazer

22 Entrevista com Lino Corrêa de Araújo. Depoimento citado. 
uma estatística para verificar quanto em dinheiro adquiria cada carreteiro, mas evidenciar a singularidade que cada um possuía e como expressavam formas de administrar seus ofícios. A postura adotada pelo entrevistado permite remeter ao que Thompson chamou de conflito em torno dos costumes, ao analisar a sociedade inglesa do século XVIII ao XIX.23

Resguardando as diferenças de espaços e tempos históricos, podemos dizer que o narrador, ao se preocupar em organizar as finanças familiares, controlando o que ganhava e gastava, deixa pistas para percebermos como sua família começou a abandonar antigas práticas constituídas em seus lugares de origem, incorporando novos costumes criados por uma economia de mercado em constituição, sem perder dimensões de seus modos de ser, viver e relacionar-se em novos contextos.

O espaço urbano melgacense começou a reconfigurar-se, a partir da década de 1960. Mas, até meados de 1980, era um lugar que guardava muitos traços do viver na floresta (PACHECO, 2006). À medida que a cidade cresceu e passou a se relacionar com pessoas vindas de outras cidades da região marajoara ou de cidades paraenses, muitos dos costumes foram se alterando. Contudo, não podemos pensar que houve um rompimento brusco e imediato com as antigas tradições ali constituídas. Isso se torna perceptível se ainda observarmos cidades paraenses que, aparentemente urbanizaram-se, desde o processo de colonização da Amazônia, a exemplo do que aconteceu com a capital do estado do Pará, Belém. ${ }^{24}$

23 Conforme Thompson, "o processo do capitalismo e a conduta não econômica baseada nos costumes estão em conflito, um conflito consciente e ativo, como que numa resistência aos novos padrões de consumo ("necessidades"), às inovações técnicas ou à racionalização do trabalho que ameaçam desintegrar os costumes e, algumas vezes, também a organização familiar dos papéis produtivos" (THOMPSON, 1998, p.21).

24 Mesmo nesse lugar, costumes e tradições de moradores que vivem nas margens do 
Através do depoimento de seu Lino, não podemos esquecer que a composição familiar desses trabalhadores revela muito das suas condições de existência; ficar apenas na análise dos valores expressos não permite entender seus modos de vida e trabalho. As famílias desses trabalhadores são numerosas. Seu Lino era pai de 07 filhos, como seu Daniel; já seu Moacir tinha 10 filhos e Haroldo, o mais novo, já possuía três. Esse aspecto, além de compor o universo da cultura marajoara, evidencia dificuldades dessas populações que se deslocam da mata para criar, educar e acompanhar trajetórias de seus filhos na cidade.

O caderno de anotações dos recursos adquiridos no trabalho com carros de mão sinaliza como seu Lino planeja seu viver familiar na cidade. Nesse contexto de organizações elaboradas por esses trabalhadores urbanos, surpreende também como Moacir apreende esse universo de preocupação com o viver futuro em Melgaço. "A gente tem que previnir um futuruzinho pra gente e a gente faz um depositozinho de um real também por dia. Eu ajunto ele e coloco no banco só de uma vez por mês. Quando a gente cair numa enfermidade a gente tem onde lançar a mão, né". ${ }^{25}$

Procurar fazer uma poupança para prevenir momentos de enfermidade na família era uma solução encontrada para que Moacir planejasse o seu futuro. Mas que futuro pode esperar com uma poupança de R \$ 30,00 por mês? Essa pergunta poderá invadir a reflexão do leitor. O carreteiro responde que não é um futuro, é um futuruzinho. Qual o sentido semântico da expressão utilizada pelo narrador? Será que devido sua condição social pensa seu futuro como menor do que o das

rio Guamá, que banha Belém, ainda lutam em permanecer como práticas culturais desses moradores, além de outros exemplos que poderiam ser captados nas vivências em vários bairros da cidade. Essas cidades, com suas particularidades e diferenças, convivem com intensos conflitos de valores e costumes para os quais chamou atenção Thompson (1998).

25 Entrevista com Moacir Ferreira. Depoimento citado. 
outras pessoas que possuem condições de depositar, em sua poupança, várias vezes a mais do que ele?

O sonho de todo trabalhador não diminui em função da situação em que vive; suas expectativas muitas vezes superam as condições materiais que lhes permitem ter modos de vida mais dignos. A revelação feita por Moacir ajuda a pensar nas condições de trabalho a que esses carreteiros estão submetidos. Por serem trabalhadores autônomos e não terem formado um órgão que os represente frente aos direitos de seguridade social, acabam sendo obrigados a criar suas próprias condições de lutarem pelo direito à saúde e à própria vida. Em outra dimensão, o depoimento possibilita perceber as dificuldades que os moradores melgacenses enfrentam para obterem do poder público, ajuda no tratamento de casos de doenças que afetam constantemente o município.

Consciente do trabalho pesado e desgastante que desenvolve, a narrativa de Moacir permite dialogar com Alessandro Portelli, nas reflexões que o intelectual italiano faz em torno da memória como um campo de possibilidades. Prevenir a vida em função de alguma enfermidade, capaz de surpreender o trabalhador, não significa que a doença esteja batendo em sua porta, "mas a possibilidade de que isso possa acontecer é uma possibilidade com que todos os indivíduos vivem, mesmo que isso não aconteça com cada um". ${ }^{26}$ Nesse sentido, o trabalho com depoimentos orais sugere compreender os sujeitos agindo e falando, a partir de seus pontos de vista, e não apenas reproduzindo discursos que pretendem homogeneizar suas ações e apagar suas diferenças.

26 Continuando essa reflexão o autor nos diz que "o relato mais representativo é o que abre mais possibilidades, e é sempre o relato individual, é o relato que combina mais motivos narrativos, mais elementos básicos da narração" (ALMEIDA \& KOURY, $2001 \mathrm{e}$ 2002, p. 32-33). Ver aprofundamentos dessas discussões em (PORTELLI, 1996). 
Antes de ser intensificado o trabalho com carros de mão na cidade, muitas pessoas, quando viajavam para fazer compras ou passear, tanto em Breves, quanto em Belém e outros municípios marajoaras ou não, procuravam avisar aos filhos ou parentes o dia de sua chegada, para que estes fossem ao trapiche ajudá-los a carregar as bagagens e compras que traziam. Com a intensificação do número de carreteiros na cidade, no contexto da década de 1990, e pelo baixo valor cobrado por esses trabalhadores para transportar materiais, essa prática diminuiu significativamente. Durante os primeiros anos do século XXI, as pessoas passaram a usar, com mais frequência, as atividades desses trabalhadores que saíam com seus carros, percorrendo a cidade, do porto às mais diversas ruas. Aspecto importante é que, nesse viajar entre cidades marajoaras, determinados moradores, por possuírem bicicletas e motos, meios de transporte muito presente no cotidiano urbano $^{27}$, pela facilidade de manuseio, às vezes levam tais meios de transportes consigo para a cidade que se dirigem, a fim de facilitarem seus deslocamentos e ao mesmo tempo carregarem suas compras. No entanto, quando os bens adquiridos são em maior quantidade, também acabam utilizando o trabalho dos carreteiros.

$\mathrm{Na}$ mudança do ambiente de trabalho, esses novos personagens, ao começarem a trafegar pelas ruas da cidade, vão redimensionando sua cartografia, imprimindo, nos espaços por onde caminham, outros tipos de relações sociais, que, apesar de diferenciarem-se daquilo que experimentaram na floresta, no contato com parentes, amigos e vizinhos, permitem reavivar laços de solidariedade, recompondo dimensões profundas de sociabilidades comunitárias, saberes que consigo carregam ao migrarem para a cidade. Frente a esta problemática, Ecléa 27 No final da primeira década do século XXI, os mototaxistas passaram a roubar as cenas da cidade-floresta. Disputando usuários e mercadorias como malas, sacolas e caixas, com os antigos carreteiros, essa nova categoria de trabalhadores urbanos conectou o município no novo modo de se lutar pelo sustento em outras cidades paraenses. 
Bosi (1999, p. 447), argumenta que "nós nos adaptamos longamente ao nosso meio, é preciso que algo dele permaneça para que reconheçamos nosso esforço e sejamos recompensados com estabilidade e equilíbrio". O que permanece na vida desses sujeitos sociais que deixaram a floresta e se encontram em territórios da cidade?

As práticas sociais estabelecidas em um determinado lugar, ao migrarem para outro, ainda que sejam espaços diferentes, tendem a construir seus pontos de encontro. Esses laços a partir de saberes, atitudes e valores, no entanto, não ocorrem da mesma forma. O que permanece é o sentido de vislumbrar a experiência vivida e não a ação tal e qual foi vivenciada. Assim, podemos perceber que, trafegando as ruas, falando ou gritando de longe com transeuntes ou pessoas que ficam na janela a expiar os movimentos da cidade, fazendo saudações, ajudando uma pessoa doente que não pode se movimentar, ou solidarizando-se com os próprios amigos de profissão quando precisam de ajuda em função do pneu do carro que furou ou qualquer outro tipo de ajuda, esses trabalhadores demonstram que o viver na cidade nem sempre apaga as possibilidades de comunicação entre as pessoas. "A vida do grupo se liga estritamente à morfologia da cidade: esta ligação se desarticula quando a expressão industrial causa um grau de intolerância de desenraizamento" (BOSI, 1999, p. 447).

As reflexões de Ecléa ajudam a pensar que as formas de comunicação nas cidades, estão ligadas a maneiras como a "modernidade" penetra seus espaços. Melgaço, por ser uma cidade construída por pessoas que experimentaram formas de organização diferente daquelas que lidam com valores e práticas capitalistas nas suas formas mais racionais, os viveres e saberes de seus moradores se expressam no tecido social que constituía/reconstitui este lugar. Contudo, não podemos afirmar que a cidade-floresta, por encontrar-se isolada dos grandes 
centros econômicos da região amazônica e do país, esteja livre dos males que a nova face de relações de mercado vem impondo a diferentes lugares e modos de vida que as pessoas constroem.

O processo de desenraizamento, apontado por Ecléa, começou em Melgaço de forma sutil, pouco visível em seu primeiro momento. A presença de meios de comunicação de massa, com sua proposta de homogeneizar costumes, invalidando saberes que davam conta de responder a necessidades de seus moradores, por meio da entrada maciça de aparelhos televisivos em quase todas as casas e jogos de vídeo games, em alguns pontos da cidade, indicam que a cidade, aos poucos, foi se modificando. Exemplar desse processo é que práticas de cura, forjadas pela medicina popular, estão sendo substituídas pelos analgésicos e diversos outros tipos de remédios da medicina industrial. Paulatinamente, as pessoas vão perdendo seus costumes em virtude da propagação de outras propostas de viver.

Frente às funções que os carreteiros vão assumindo na cidade, estes se tornam, também, os que mais conhecem o viver das pessoas. Ao trafegarem por todos os cantos do espaço urbano e de sua periferia, carregando diversas cargas em movimentos, sabem o que a cidade compra e vende, o que entra e sai, o que as pessoas adquirem para suas casas, fazendo-os conhecedores dos poderes aquisitivos dos diferentes moradores. Ainda nesse universo de envolvimento intenso com a dinâmica da cidade, tomam conhecimento dos boatos, mexericos, fofocas, desavenças e confusões que atravessam o cotidiano do lugar, percebendo comportamentos, posições e posturas de seus moradores. Podemos dizer que os carreteiros são os que, ao ajudarem a tecer uma cartografia sensível ou os mapas afetivos da cidade (BOSI, 1999, p. 444), permitem visualizar múltiplos significados do que é ser morador e trabalhador deste lugar, sendo, portanto, um dos seus construtores. 
Não são, contudo, os únicos responsáveis por essa construção, e os que imprimem uma compreensão e sentido único do que é uma cidade marajoara, pois entendemos que "a constituição do espaço urbano se dá no conjunto das experiências sociais e não de forma isolada, como ato de apenas uma única pessoa" (LACERDA, 1999, p. 206) ou grupo social.

Aprofundando a questão anteriormente mencionada, a respeito dos materiais que os carreteiros transportam, é perceptível como a cidade cresce com a chegada de outros moradores e o surgimento, ou aumento de entrada de dinheiro, ${ }^{28}$ estimulando o desenvolvimento do comércio local, modificando demandas de consumo.

Olha numa linguagem assim, no caso de aumentado, tem aumentado muito no caso da mercadoria que vinha há cinco anos atrás. Quando eu comecei a carregar era pouca, hoje no decorrer dos anos a gente nota que cada vez mais aumenta a mercadoria aumenta mesmo, aceleradamente, a própria madeira aumenta muito, telha, tijolo isso aí tem tido um crescimento muito grande. ${ }^{29}$

Teve uma mudança porque agora nesses quatro anos, a gente vê que carrega muito ferro, né, madeira que realmente de primeiro compravam mais pouco e agora passaram a comprar mais, até mesmo cimento (...) estão comprando mais alguma coisa. ${ }^{30}$

28 No ano de 2001, foi implantado na cidade o Programa Nacional Bolsa escola que passou a atender mais de 1300 famílias de todo o município. Houve também um aumento do número de aposentados que recebem seus benefícios na cidade. Esse aumento se deu por dois motivos. Primeiro pela transferência do posto de pagamento que antes acontecia em Breves, onde muitos dos idosos tinham que ir se deslocar àquela cidade receber seus vencimentos. Agora a maioria recebe na agência dos correios em Melgaço. Segundo por causa do aumento da população no município e o consequente envelhecimento de alguns moradores. O pagamento da Bolsa-Escola que acontece no posto da caixa econômica, instalado na farmácia Viegas e o pagamento dos aposentados na agencia dos correios em Melgaço, segundo os comerciantes que entrevistamos, confirmam que o fluxo de dinheiro na cidade aumentou.

29 Entrevista com Lino Corrêa de Araújo. Depoimento citado.

30 Entrevista com Moacir Ferreira. Depoimento citado. 
As novas construções que começaram a ser erigidas na cidade no final dos anos de 1990, tanto por parte do poder público - como asfaltamento ou melhoramento das principais ruas, construção de prédios (prefeitura municipal, residência dos médicos, escolas municipais e estadual, projeto casa de farinha, trapiche municipal, mercado municipal, etc.); - quanto do capital privado (prédio para o funcionamento da rede Celpa) ou por parte dos moradores (abertura de casas comerciais, habitações de madeira coberta com palha, telha de barro ou de brasilit, construções de casas de alvenaria, hotel, barracas de vendas) foram impulsionadas pelo trabalho dos carreteiros.

A atuação desses trabalhadores nos espaços da cidade tem sido algo muito perceptível e consciente, como podemos perceber no relato de seu Lino: "aonde estão armando um barraco lá a gente chega transportando o material". ${ }^{31}$ Por dentro e por fora, ${ }^{32}$ esses trabalhadores, carregando mercadorias diversas, estivas, armarinhos e também madeira, cimento, ferro, tijolo, pedra, telhas, palhas, sacolas de pessoas que chegam na cidade ou dos moradores que retornam de suas viagens, vão empreendendo no cotidiano do lugar, seus ritmos e modos de trabalho, evidenciando a importância de suas atividades para o crescimento de Melgaço.

O trabalho do carreteiro ele tá sendo importante pra cidade porque as pessoas fazem sua compra e não tem como transportar e o carreteiro que tem seu carro, favorece para as pessoas que tem esses materiais pra carregar para as suas casas. ${ }^{33}$

Somos úteis, para a cidade, para a sociedade, porque somos nós que transportamos os materiais que vem de fora, somos nós que traz o material daqui, os que sai, então somos nós que estamos naquela lida, leva, traz, então eu acredito que é esse o porque, é útil a sociedade, porque Melgaço como uma sociedade pequena que ainda

31 Entrevista com Lino Corrêa de Araújo. Depoimento citado.

32 Essa expressão foi possível ser construída, pelas informações que seu Lino nos deu, dizendo que esses trabalhadores carregam materiais de fora e de dentro da cidade.

33 Entrevista com Moacir Ferreira. Depoimento citado. 
não tem carretas, caminhão, isso desse serviço, então tem que ser o nosso serviço. ${ }^{34}$

Conscientes de seu papel enquanto atores sociais responsáveis por transportar o "progresso" e os ensaios de uma possível modernização da cidade, impulsionada pela ação do poder público na construção de novos empreendimentos nesse espaço urbano, os carreteiros, no entanto, alertam, revelando o lugar onde trabalham e as características desse espaço: "sociedade pequena", sem outros tipos de veículos para transportar o que a cidade consome. ${ }^{35}$ Suas histórias, todavia, não se constroem de forma romântica, sem conflitos como poderia parecer à primeira vista. Relações diversas se forjam entre moradores, usuários e carreteiros.

Sobre essa relação, narra Haroldo: "Bom tem pessoas que são importantes sobre isso aí, no pagamento sobre o trato, agora tem pessoas que são meio cruéis. Tem que cobrar duas ou três vezes, às vezes eu acho melhor larga de mão, que não recebe". ${ }^{36}$ Acompanhando outra narrativa a respeito dessa relação entre os usuários dos serviços do carreteiro, descobrimos: "Tem vez que são fiel, tem vez que deixam pra depois e aí uns não paga, e a gente vai levando o trabalho, assim um tempo a gente perde, outro tempo a gente ganha". ${ }^{37}$

Intensificando nossa compreensão sobre o olhar que os carreteiros desenvolvem a respeito dos moradores da cidade que utilizam seus serviços, seu Lino também faz sua avaliação: "Tem pessoas mesmo

34 Entrevista com Lino Corrêa de Araújo. Depoimento citado.

35 Apenas um comerciante na cidade possui um veículo automotivo, comprado de segunda mão para transporta suas mercadorias do porto para seu comércio.

36 João Haroldo Marques de Araújo, 29 anos, há 09 anos residem em Melgaço, filho de seu Lino que também é carreteiro, Melgaço, 01 de dezembro de 2002.

37 Entrevista com Daniel Pinheiro da Silva. Depoimento citado. 
aqui em Melgaço, que chega os barcos olha mercadoria do fulano, não tem quem queira carregar, mas isso é uma minoria, sempre todo mundo trata bem, paga bem". ${ }^{38}$

A maneira como os carreteiros vendem seus serviços aos moradores não pode ser pensada de forma isolada e fria. Torna-se necessário envolver-nos nos trâmites das relações que estabelecem com essas pessoas, tentando investigar quem são esses usuários? São parentes, amigos, conhecidos, desconhecidos? Suas atitudes? Qual seu poder de compra? Como esses trabalhadores relacionam-se entre si? Esse relacionamento ocorre de forma igual? E os moradores, o que pensam desses carreteiros? Como se relacionam com cada um? Têm preferência na escolha de quem vai fazer seu carreto?

Desenhando o mapa desses perfis humanos que dão concreticidade a essas relações, configurando os rostos de moradores que utilizam o meio de transporte dos carreteiros, faz-se necessário dizer que essas pessoas eram professores, trabalhadores do setor público que estão nos mais diferentes cargos da administração municipal, trabalhadores da área de saúde, funcionários públicos federais e estaduais do fórum, correios. Ou da esfera privada, como pequenos e médios comerciantes, donos de farmácia, hotéis, bares, restaurantes; ou ainda trabalhadores rurais, como agricultores, lavradores, palmiteiros, pescadores, donos de batedeiras de açaí, aposentados e ainda desempregados. Enfim, podemos dizer que os moradores que constituíam o patrimônio humano de Melgaço (CALVO, 2001), utilizam-se, na sua maioria, dessa forma de trabalho urbana que foi "inventada" na cidade pelos antigos trabalhadores rurais.

38 Entrevista com Lino Corrêa de Araújo. Depoimento citado. 
Retomando as indagações acima formuladas e o que narram esses trabalhadores a respeito das pessoas que fazem usos de seus serviços, como ainda observando atitudes desses usuários em relação aos carreteiros, podemos dizer que há um jogo duplo: se há uma espécie de seleção por parte dos carreteiros nos transportes das mercadorias de certas pessoas, porque lhe tratavam bem e pagavam o serviço corretamente, há que se notar que esses moradores também tinham suas preferências. Nesse jogo de escolhas, carreteiras e moradores iam tecendo relações sociais que extrapolavam o campo da pura e simples compra de um serviço, alianças, desconfianças, tensões, amizades e sociabilidades também ali iam se constituindo.

Atentos ao cotidiano de trabalho desses carreteiros e observando detalhes no seu relacionamento com os moradores e a cidade, uma prática extremamente significativa foi se revelando ao longo da pesquisa de campo e pode exemplificar o jogo de escolhas do qual estávamos falando. Qual seja: todas às vezes que o barco da linha, que fazia o percurso Melgaço e Breves ou vice-versa, ao retornar de Breves, entre $12: 00 \mathrm{~h}$ a $13: 00 \mathrm{~h}$ da tarde, e começava a se aproximar do porto de Melgaço entre as 15:00h ou 16:00h, antes de atracá-lo, ainda de dentro do barco, esses passageiros faziam suas escolhas através de sinais realizados com as mãos para o carreteiro escolhido. Esses jogos de sinais só eram compreendidos por quem vivenciava esses processos de comunicação.

\section{Revendo o Mapa Tracejado}

Tentar apreender o movimento social onde estavam inseridos esses trabalhadores, acompanhando suas ações, gestos, atitudes e comportamentos foi tarefa fundamental para se compreender como esses 
protagonistas do viver urbano agem através de suas individualidades e posicionamentos específicos e de que forma interpretam suas experiências com o trabalho em carros-de-mão. Nesse sentido, consideramos que esses carreteiros podem ser vistos como constituindo um grupo social na cidade de Melgaço.

O integrar-se neste ofício ou sua resistência para aceitá-lo, traduz percepções diferenciadas em torno das tarefas que pretendem desenvolver para garantir o sustento de suas famílias. Para isso foi preciso compreender esses carreteiros em universo relacional, munidos de vontades próprias e interesses particulares. Analisá-los como homens que possuem atitudes específicas, não significa dizer, todavia, que são individualistas, pois estão inseridos em dinâmicas sociais que ora podem uni-los, ora podem distanciá-los.

Os modos de vida desses trabalhadores eram mediados por questões de ordem material e simbólica que, por sua vez, remetiam para costumes e formas específicas de apreenderem o mundo e as maneiras de viver. Migrar de um lugar para o outro, mesmo em se tratando de espaços já conhecidos, representa, muitas vezes, esfacelamentos em relações de trabalho e de parentesco antes constituídas. Muitos homens, mulheres e crianças ao saírem dos territórios da floresta, deixando pedaços de terra, plantações, casas, marcas de suas vivências e culturas rurais, ao cruzarem territórios da cidade, sentiram-se estrangeiros. O sentimento de pertencimento que viviam em sua pequena propriedade na floresta, muitas vezes não conseguia ser refeito na vida urbana. $\mathrm{O}$ novo espaço que elegeu para morar, à proporção que foi se alterando, força-os a refazerem-se enquanto agentes sociais, sendo obrigados a reconstituírem saberes, experiências, tradições, costumes para entrarem em sintonia com viveres na cidade. 
Para alguns, o esfacelamento dos referenciais que lhes davam inteligibilidade para relacionarem-se com pessoas que faziam parte de seu meio físico e social foi tão forte que, não suportando, retornaram ao lugar de origem, passando a ver a cidade como um território que lhes negava a condição cidadã e os saberes que possuía para continuar lutando pela vida. Para outros, persistindo em encontrar indícios e traços de suas culturas e tradições constituídas na floresta, em injunções que implementam entre seus conhecimentos marcados por uma forte presença de matrizes orais, e as linguagens urbanas, vão refazendo suas identidades e tornando-se moradores e trabalhadores da cidade.

Ao chegarem à cidade, com o sonho de conseguirem empregos, esses habitantes da floresta esbarraram na falta de conhecimentos e habilidades que os poucos postos de trabalho existente na cidade exigiam, ou então na falta de uma profissão que os citadinos sempre recorrem - carpinteiro, marceneiro, encanador, eletricista, calafate, consertadores de objetos diversos e outros. Dos trabalhadores que entrevistamos, todos são alfabetizados, porém estudaram até o primeiro grau menor ( $1^{\mathrm{a}}$ a $4^{\mathrm{a}}$ série $),{ }^{39}$ outros sabem apenas assinar o nome. Esse jogo entre oral e escrito não pode ser pensando apenas do ponto de vista do confronto e negação, há que se refletir sobre suas injunções presentes nas relações que esses migrantes do meio rural estabelecem com os diversos moradores da cidade.

Por serem trabalhadores que dependiam dos chamados da cida-

39 Dos carreteiros entrevistados apenas Moacir, alguns anos depois que chegou na cidade voltou a estudar, em 2001 cursava a $5^{\text {a }}$ série, mas em seguida abandonou a escola porque o trabalho não lhe permitia conciliar com o estudo. E perguntando para Haroldo sobre a vontade de continuar estudando me revelou que perdeu p estímulo, quer apenas proporcionar condições para os filhos continuarem estudando. Nesse sentido, a educação ganha outro significado na fala desse trabalhador. 
de, a chegada dos barcos apresentava-se como oportunidade indispensável na aquisição de trabalho. Nesse momento, cargas, sacolas e compras se apresentavam como possibilidade de obter dinheiro naquele dia. Desse modo, aumentar o ritmo na atividade era fundamental no processo de trabalho, pois quanto mais rápidos fossem no transporte das mercadorias que estavam no porto aguardando entrega, maior seria o número de carretos possíveis de serem realizados. Nesse contexto, podemos perceber que o trabalho com carro-de-mão, não somente na região marajoara e amazônica, mas também em outros centros urbanos do Brasil, como observou Luzia Silva (2003, p. 151-152) no trabalho que desenvolveu sobre os carregadores de mercadoria em Uberlândia, onde "a imprevisibilidade do trabalho e conseqüentemente dos ganhos é uma realidade para todos". E ainda assinalou "nos modos de trabalhar desses carregadores se alternam longas esperas e pouco trabalho, com jornadas muito intensas, quando existe o trabalho".

Nesse universo de relações, de um lado representado por aqueles que se utilizam do trabalho desses trabalhadores - prefeitura, casas de comércio, moradores - e de outro, os que vendem esse tipo específico de serviço - os carreteiros, um princípio básico mediatizava a relação: o princípio da honestidade. ${ }^{40}$ Cada carreteiro tinha consciência de que o extravio, desaparecimento ou danificação de qualquer objeto transportado, o levaria à perda da confiança dos usuários e, automaticamente, poderia ser excluído da profissão que exercia. A honestidade

40 Sobre esse princípio humano exigido no trabalho com transporte de cargas, Luzia em sua tese de doutorado, mas especialmente no capítulo II quando discute a batalha dos carregadores de mercadorias para pleitear oportunidades de trabalho por meio da organização sindical, analisa por meio de depoimentos orais que trazem de forma enfática o papel da honestidade, como esse princípio mediatiza as relações de trabalho entre carregadores e firmas atacadistas em Uberlândia. Ver melhor em (SILVA, 2001, p 111 e p. 113). 
no trabalho emergia, então, como senha, código de conduta elaborado pelos próprios trabalhadores.

Vale lembrar ainda que estudar o tema do trabalho dos carroceiros é compreender que suas trajetórias são partes integrantes da própria história dos trabalhadores no Brasil. Histórias marcadas por migrações recorrentes, por preconceitos, estranhamentos, discriminações, desigualdades, explorações sociais e intolerâncias.

Por esse enredo cartográfico, tentamos apreender as formas de ser, relacionar-se e trabalhar de habitantes da floresta que se fizeram trabalhadores urbanos em contato com formas de viver na cidade. Partimos do princípio de que ao fazerem-se novos habitantes de Melgaço, contribuíram também para que, com seu trabalho, com suas formas de morar e agir, a cidade fosse multiplicando e modificando características e feições. Tentamos não homogeneizar suas ações ou procurar elementos que pudessem identificá-los como parte integrante de uma pretensa memória coletiva ${ }^{41}$ sobre a cidade. Atentos a seus falares, carregados de emoções, foi possível sondar suas subjetividades, tanto no que dizia respeito aos valores que a cidade atribuía a suas atividades, quanto aos significados que esta lhes representava.

\title{
CARTOGRAPHY OF LABOR IN THE CITY-FOREST
}

\begin{abstract}
This article is intended to map movements and senses undertaken by rural and forestal inhabitants from the city of Melgaço who work with barrows. Melgaço is located in the

41 Alessandro Portelli (1997, p. 31) nos diz que "quando trabalhamos com a História Oral o que vemos é mais a memória que cada ser humano tem individualmente. (...) Nossa experiência é uma experiência social, mas não se pode submeter completamente a memória de nenhum indivíduo sob o marco da memória coletiva. Cada pessoa tem uma memória, de alguma forma, diferente de todas as demais. Então, o que vemos, mais que uma memória coletiva, é que há um horizonte de memórias possíveis".
\end{abstract}


archipelago of Marajó, in the Brazilian State of Pará. To achieve this goal, oral memories from those migrant workers, captured in interviews, interact with concepts of oral, social and culture history. It is done so to put in evidence experiences of work, negotiations and political struggles that re-signified ways of life in this city-forest in the last decade of the twentieth century.

KEYWORDS: Cartography. Memory. Experience. Labor. City-Forest.

\section{REFERÊNCIAS}

ALMEIDA, P. R. de; KOURY, Y. A. História Oral e Memórias entrevista com Alessandro Portelli. História \& Perspectiva, Uberlândia/MG, n. ${ }^{\circ}$ 25/26, jul/Dez 2001 e Jan/Jun 2002.

BALCÃO, L. F. A cidade das reclamações: moradores e experiência urbana na imprensa paulista (1900-1913). Dissertação de Mestrado em História, PUC-SP, 1998.

BOSI, E. Memória e Sociedade: lembrança de velhos. 7. Ed. São Paulo: Cia. das Letras, 1999.

CALVO, C. R. C. Muitas memórias e histórias de uma cidade: experiências e lembranças de viveres urbanos - Uberlândia, 1938/1990. Tese de Doutorado em História, PUC-SP em 2001.

CERTEAU, M. A cultura no plural. Tradução Enid Abreu Dobránszky. Campinas, SP: Papirus, 1995. (Coleção Travessia do Século)

CORPO E CULTURA. Projeto História 25. São Paulo: EDUC, dezembro de 2002.

FERREIRA, J. S. Memória, História e Trabalho: as experiências das trabalhadoras domésticas na cidade de Uberlândia/MG - 1970-1999. Dissertação de Mestrado em História, PUC/SP, 2000.

GIL, José em entrevista à SANT'ANA, Denise. Cadernos de Subjetividade, SP, EDUC, vol.5, nº 02, 1997.

LACERDA, F. G. Cidade, memória e experiência ou o cotidiano de uma cidade do Pará, nas primeiras décadas do século XIX. In: FENELON, Déa Ribeiro. Cidades, Pesquisa em História 01, Programa de Estudos Pós- 
Graduados em História PUC-SP, São Paulo: Olho d'água, 1999. MACIEL, L. A. \& ANTONACCI, M. A. Espanhóis em São Paulo: modos de vida e experiências de associação. Projeto História 12, São Paulo: PUC/SP, 1995, p.173-192.

MARICATO, E. Brasil, cidades: alternativas para a crise urbana. Petrópolis, Rio de Janeiro: Vozes, 2001.

MARTÍN-BARBERO, J. Ofício de cartógrafo: travessias latino-americanas de comunicação na cultura. Tradução Fidelina González. São Paulo: Loyola, 2004.

MORAIS, S. P. Trabalho e Cidade: Trajetórias e vivências de carroceiros na cidade de Uberlândia, 1970-2000. Dissertação de Mestrado. Instituto de História da UFU, Uberlândia, 2002.

PACHECO, A. S. À Margem dos "Marajos": cotidiano, memórias e imagens da "cidade-floresta"- Melgaço-PA. - Belém: Paka-Tatu, 2006.

PACHECO, A. S. En el Corazón de la Amazonía: identidades, saberes e religiosidades no regime das águas marajoara. Tese de Doutorado em História, PUC-SP, 2009.

PORTELLI, A. "A filosofia e os fatos". Tempo, vol. 01, n. . 02, UFF/Relume Dumará, 1996, p. 59-72.

PORTELLI, A. Tentando aprender um pouquinho: Algumas reflexões sobre a ética na História Oral. A pesquisa como um experimento em igualdade. Projeto História, 15, São Paulo, EDUC, abril/1997, p. 13-33.

SANTANA, C. A. A domesticação de corpos da cidade. Projeto História 25, São Paulo: EDUC, dez/2002, p. 313-323.

SANTANA, C. A. Fartura e Ventura camponesas: trabalho, cotidiano e migrações. São Paulo. Anna Blume/ UEFS, 1998.

SILVA, L. M. R. Carregadores de mercadorias: memórias e lutas. Uberlândia-MG 1970-2000. Tese de Doutorado em História, PUC-SP, 2003.

SOUZA, J. C. Na luta por habitação: a construção de novos valores, São Paulo: Educ, 1995. 
THOMPSON, E. P. A Miséria da Teoria - ou um planetário de erros. Rio de Janeiro, Zahar Editores, 1981.

THOMPSON, E. P. A Formação da classe operária inglesa - A árvore da liberdade. $3^{\text {a }}$ edição, V. 1. Rio de Janeiro: Paz e Terra, 1987.

THOMPSON, E. P. Costumes em Comum: estudos sobre a cultura popular tradicional. São Paulo: Cia das Letras, 1998. ZUMTHOR, P. Performance, recepção, leitura. SP: Educ, 2000. 